\title{
The Influence of Nutrition Status on Executive Function of Early Childhood Education in DKI Jakarta Province
}

\author{
Debie Susanti, Myrnawati Crie Handini, Elindra Yetti \\ Department of Early Childhood Education, Jakarta State University, Jakarta, Indonesia
}

Email address:

drdebiesusanti@yahoo.com(D.Susanti),myrnawati@unj.ac.id(M.C.Handini),elindrayetti@unj.ac.id(E.Yetti)

To cite this article:

Debie Susanti, Myrnawati Crie Handini, Elindra Yetti. The Influence of Nutrition Status on Executive Function of Early Childhood Education in DKI Jakarta Province. International Journal of Education, Culture and Society. Vol. 3, No. 2, 2018, pp. $24-27$. doi: $10.11648 /$ j.ijecs.20180302.11

Received: April 22, 2018; Accepted: May 14, 2018; Published: May 25, 2018

\begin{abstract}
The research objective was to know the influence of nutrition status on executive function to the children. The type of research used ex-post facto through survey method at six Class B early childhood education which the total number of students is 102 students who were gotten multistage cluster random sampling technique from the all students in DKI Jakarta Province. The data of children's executive function was gained through survey method and used Executive function instrument, BRIEF-P which had modified and validated. The research finding was based on analysis in this study, then concise that the children's executive function was affected by their nutrition status. To raise the children's executive function, it needs to increase their nutrition status. Likewise, the children who have good nutrition status are disposed to have good executive function. Therefore, through this research may be a suggestion for the government of Indonesia to increase the children's nutrition status in Indonesia by serving the educational program to the parents, and hold the teacher's training for PAUD teachers in order to upgrade the understanding of children executive function, thus they can restrain disturbances of learning process in the classroom.
\end{abstract}

Keywords: Nutrition Status, Executive Function, Early Childhood Education

\section{Introduction}

Young learner education is one of intervention media to increase every single aspect of children executive function, as a foundation to their success in the future. The research of brain development recently showed that there is a first experience effect of children and environment to the children brain expansion.

Executive function is very important to children growth because it will be the main foundation to decide children's school preparation [1]. The Executive function covers selfcontrol ability, work memory, and mental flexibility [2]. Executive function is a group of higher cognitive process, emotional process, and motivation, chained by brain cortex prefrontal which head for helping someone to achieve the goals and manage the change probability soon as possible in dealing a situation. This function also arranges cognitive, emotion, and someone social behavior [3].

Nevertheless, in developing the executive function will find several certain factors that influenced it directly or indirectly. The recently researches indicated the executive function connected to some factors comprised the children nutrition status. The children who have malnutrition who is lack of nutrition or over should have cognitive development disease [4]. Defined that nutrition status is a food information, laboratory, anthropometry, and somebody clinical or population which are affected by nutrition consumption and supply. Nutrition status assessment is an interpretation of its information, thus could divide nutrition status of certain person or population [5].

The data of child nutrition based on collected report of United Nations Children's Fund (UNICEF), (UNICEF), World Health Organization (WHO), and Association of South East Asian Nations (ASEAN) asserted that most of children experience to obesity, other get growing obstruction and lack of weighty. The proportion case of children's growth in Indonesia is equal that is $12 \%$ over weight, $12 \%$ other is lack of weighty [6]. The nutrition case of children which is connected to the executive function of development is still becoming an unfinished problem until now in Indonesia. 
Therefore, it is needed to do research in order to know is children's nutrition status could affect to the executive function of children five years old directly nor indirectly, especially in DKI Jakarta as Indonesian Education barometer.

\section{Research Method}

This research is an ex-post facto with survey method that conducted at Kelurahan Johar Baru early childhood education, Johar Baru sub district, Jakarta Pusat City, DKI Jakarta Province. Collecting data was conducted since April-June 2017. The sampling method was multistage cluster random sampling with the four steps. The sample collecting of secondary group was taken random, the chosen cluster was Johar Baru sub district, and consisted of six clusters they were 102 students who were choosen random as the minimal number of the samples. The chosen random cluster consisted of Indriasana early childhood education (10 students of B Class), Johar Baru of early childhood education (15 students of Class B), The one roof of early childhood education (20 students class B), Parkit KG (12 students of Class B), Islam Al Jihad of early childhood education (42 students of class B), and Aisyiyah early childhood education 97 (21 students class B).

The nutrition status data had acquainted by anthropometry measurement body higher and weight. The data of children's executive function was gained through survey method and used Executive function instrument, BRIEF-P which had modified and validated.

\section{Research Findings}

\subsection{Children's Executive Function}

The counting result of data was gained medium executive function and high 68 and 34 children. It did not find the children with low executive function. Average, executive function amount of 80.37; amount of standard deviation is 6.10; variant is about 37.2460 ; median is 83.0 ; and modus is 83 .

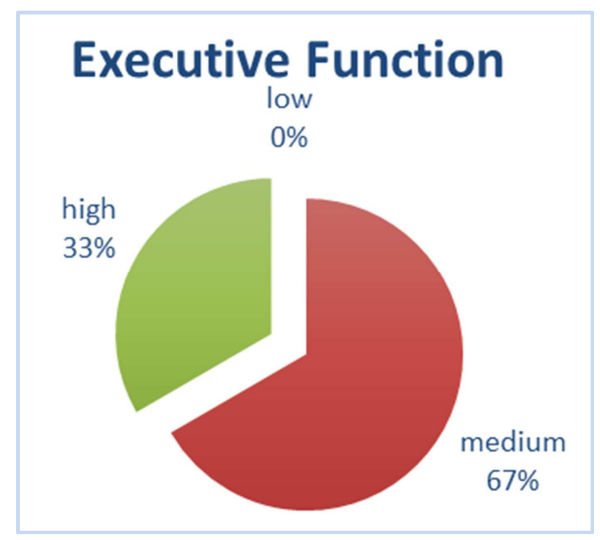

Figure 1. Data Dispersion of Executive Function.

Pointed to the result of research was known that higher executive function came from nutrition status and variety. Completely, the Data Dispersion of Executive Function and nutrition status of children could be seen in the table below:
Table 1. Data Dispersion of Executive Function Frequency based on Sex, age, and nutrition status.

\begin{tabular}{lllll}
\hline & \multicolumn{3}{l}{ Executive Function } & \multirow{2}{*}{ Total } \\
\cline { 2 - 4 } & Low & Medium & High & \\
\hline Sex & - & 33 & 14 & 47 \\
Male & - & 35 & 20 & 55 \\
Female & - & & & \\
Age & - & 16 & 3 & 19 \\
$\geq 5$ years 0 month & - & 45 & 25 & 70 \\
$\geq 6$ years 0 month & - & 7 & 6 & 13 \\
$\geq 7$ years 0 month & - & & & \\
Nutrition Status & - & - & - & - \\
Very thin & - & 2 & 5 & 7 \\
Thin & - & 45 & 28 & 73 \\
Normal & - & 8 & 1 & 9 \\
Fat & 13 & - & 13 \\
Obesity & & & & \\
\hline
\end{tabular}

\subsection{Nutrition Status}

Nutrition status data had acquainted that children spreading who with thin nutrition status, normal, fat, and obesity as follow:

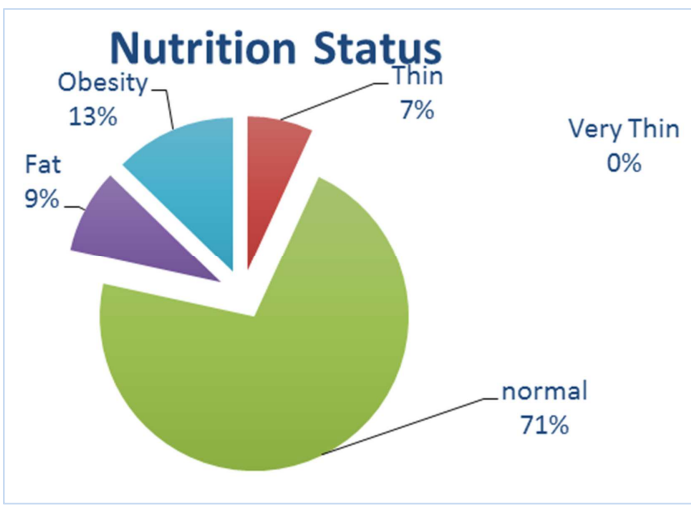

Figure 2. The Data Dispersion of Nutrition.

The most excessively Nutrition status is normal nutrition status amount of 73 children. It had not recovered children's data with very thin status. This probably because there was no gained the children data with lower economy status. The obesity children do not have higher executive function. Completely, the data dispersion of children nutrition status can be found at the table below:

Table 2. The Data Dispersion of Nutrition Status Frequency based on Sex, age, Executive function.

\begin{tabular}{|c|c|c|c|c|c|c|}
\hline & \multicolumn{5}{|c|}{ Nutrition Status } & \multirow{2}{*}{ Total } \\
\hline & Very Thin & Thin & Normal & Fat & Obesity & \\
\hline \multicolumn{7}{|l|}{ Sex } \\
\hline Male & - & 5 & 28 & 5 & 9 & 47 \\
\hline Female & - & 2 & 45 & 4 & 4 & 55 \\
\hline \multicolumn{7}{|l|}{ Age } \\
\hline$\geq 5 \mathrm{yr} 0 \mathrm{mo}$ & - & - & 13 & 3 & 3 & 19 \\
\hline$\geq 6$ yr $0 \mathrm{mo}$ & - & 6 & 50 & 4 & 10 & 70 \\
\hline$\geq 7 \mathrm{yr} 0 \mathrm{mo}$ & - & 1 & 10 & 2 & - & 13 \\
\hline \multicolumn{7}{|l|}{$\begin{array}{l}\text { Executive } \\
\text { function }\end{array}$} \\
\hline Low & - & - & - & - & - & - \\
\hline Medium & - & 2 & 45 & 8 & 13 & 68 \\
\hline High & - & 7 & 28 & 1 & - & 34 \\
\hline
\end{tabular}


Based on the table, had found that there is inclining of Executive function increasing as nutrition status development.

\section{Discussion}

Nutrition problems in Indonesia include two things, namely malnutrition or malnutrition, and malnutrition or more nutrition. Both nutrition problems are manifested directly in children, therefore, the decision of the direct nutritional status of the executive function of the child will be divided into two parts according to the nutritional problems occurring in Indonesia.

The hypothesis of analysis result found that nutrition status influenced directly positive to children's executive function. Based on the finding result, could be conclude that children's executive function was affected by nutrition status. The increasing of nutrition status will impact the rising children's executive function.

This result is similar with the research result was conducted by McCoy et al [7] at Zambia to 2711 children of 6 years old. The research result showed children nutrition status (measured by age level indicator) affected the children's executive function. Children nutrition status is connected to the children normal growth of brain. Executive function was decided by prefrontal part of the brain which undergoes disruption growth and malnutrition children.

\subsection{Less Nutrition}

Less nutrition will lead to child growth failure through acute malnutrition, including wasting, chronic malnutrition including stunting, and general weight loss covering both. Chronic malnutrition occurs gradually and in general the child looks like any other normal child, but short for a child his age.

The research finding was equal with Morgan's [8] research at Uganda. Malnutrition children indicated lower executive function than the children with normal nutrition status. This happened because there was disruption of brain growth in the prefrontal part of malnutrition children which affects to the children's executive function.

Selvam et al [9] designated the same result of research at India. This Across-slice research conducted to 412 children of 2-5 years old in Bangalore city, India. The checkup of executive function in the research was also using BRIEF-P. One of the result indicated that children who were stunting and underweight or called malnutrition showed executive dysfunction, whereas children who were having normal nutrition status showed normal executive function indeed. The executive function aspect that hampered to the malnutrition children was a work memory and ability to control their emotion. This case induced the children will be difficult to learn reading and math. Less of emotion control will cause the children hard to socialize with their friends and teachers.

Summarily, the straight effect of underweight to executive function could be seen at the following figure:

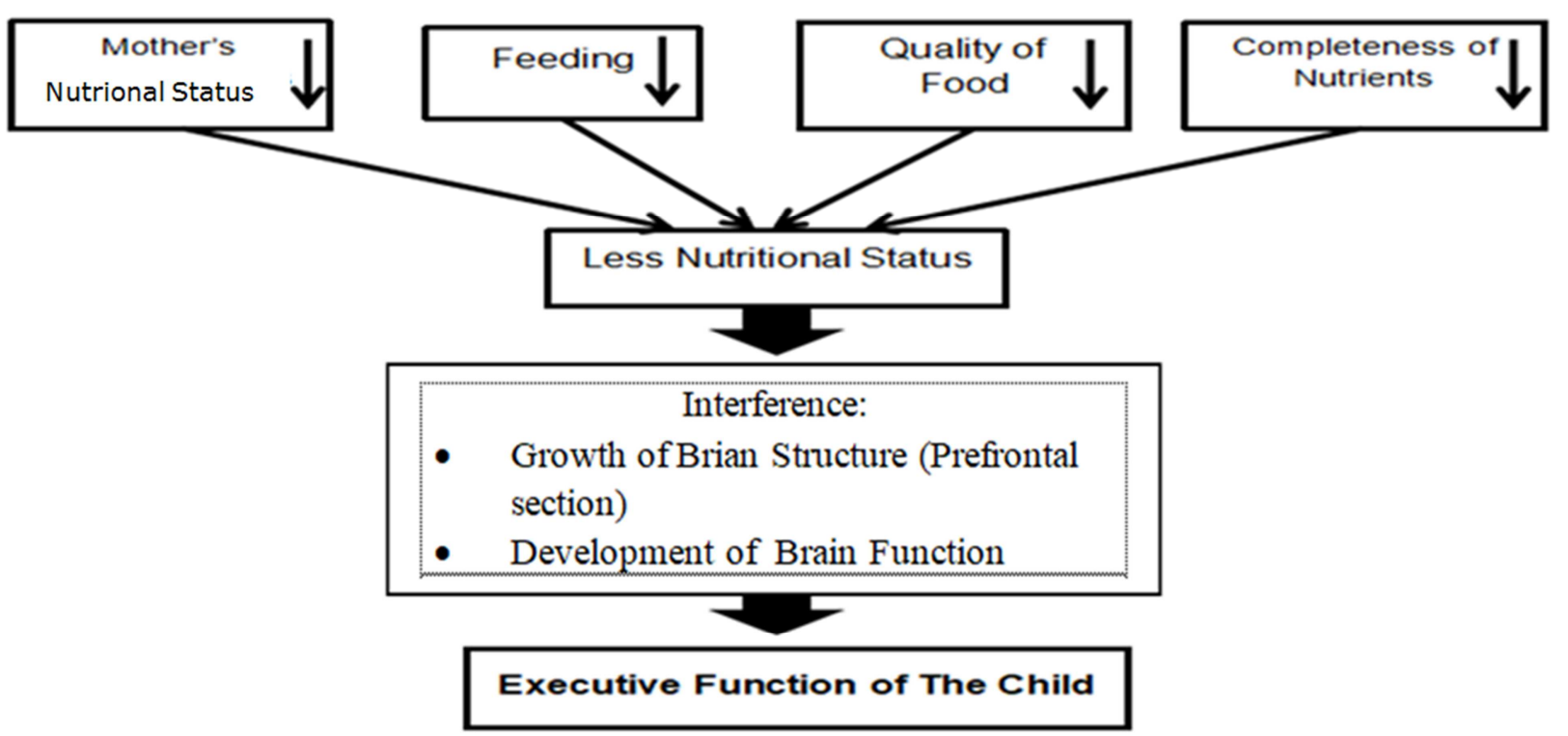

Figure 3. Straight Effect of Nutrition Status to the Executive Function.

Thus, can concise that nutrition status influence to the children's executive function. Based on the above description, it can be assumed that the nutritional status is less directly positive effect on the executive function of children. The lower the nutritional status of children, the lower the executive function.

\subsection{More Nutrition}

These more nutritional problems are associated with a high intake of foods high in fat and carbohydrates, low in nutrients. Results of research conducted by Pauli-Pott et al [10] showed there is a relationship between low self-control 
ability with excess body weight in children. Self-control is one aspect of the executive function, which turns out to be lower in children with more nutritional status.

The executive function of children with lower nutritional status when compared with normal children is the difference in brain structure measured by MRI. Based on the result of the research, it can be assumed that the nutritional status has more direct negative effect to the executive function of the child. The higher the nutritional status of children, the lower the executive function. The executive function is best if the child's nutritional status is normal.

\section{Conclusion}

The research finding was based on analysis in this study, then concise that the children's executive function was affected by their nutrition status. To raise the children's executive function, it needs to increase their nutrition status. Likewise, the children who have good nutrition status are disposed to have good executive function. Conversely, children with poor nutritional status tend to have a low executive function, given that Executive Function is very important and the basis for the development of children's learning in the future.

Therefore, through this research may be a suggestion for the government of Indonesia to increase the children's nutrition status in Indonesia by serving the educational program to the parents, and hold the teacher's training for PAUD teachers in order to upgrade the understanding of children executive function, thus they can restrain disturbances of learning process in the classroom.

For Central Jakarta social workers to empower people belonging to people with lower middle economy through family economic empowerment activities such as home industry skill activities, income improvement and nutritional status of children will be improved.

\section{Acknowledgements}

The author thanks to the financial support for the research conducted by institution managing education fund (LPDP) Indonesia (process N. PRJ-1523/LPDP.3/2017).

\section{References}

[1] Rothlisberger Marianne, Regula Neuenschwander, Patriza Cimeli, et al, Improving executive function in 5- and 6-years olds: Evaluation of a small group intervention in prekindergarten and kindergarten children, Infant and Child Development, vol.21, 2012. p. 411

[2] Felver Joshua C., Marcie Yeager and Daniel Yeager: Executive Function \& Child Development, J Child Fam Stud, vol.23, 2014, p 945

[3] Jimenez Eva Angelina Araujo, MA. Claustre Jane-Ballabriga, Albert Bonillo Martin, et al, Executive Function Deficits and Symptoms of Disruptive Behaviour Disorder in Preschool Children, Universitas Psychologica Vol. 13:4, 2014, p 1267

[4] Bauer, C. C. C, B. Moreno, L. Gonzales-Santos, et al, Child overweight and obesity are associated with reduced executive cognitive performance and brain alteration: a magnetic resonance imaging study in Mexican children, Pediatric Obesity, vol. 10, 2014, pp. 196-204

[5] Gibson Rosalind S., Principles of Nutritional Assessment, New York; Oxford University Press, 2005, p 2

[6] Anon, Obesitas dan malnutrisi, dua masalah anakIndonesia, BBC Indonesia, 31 Maret 2016, http://www.bbc.com/ indonesia/berita_indonesia/2016/03/160331_indonesia_unicef _gizi (diunduh 30 Oktober 2016)

[7] McCoy, Dana Charles, Stephanie Simmons Zuilkowski, et al, Poverty, physical stature, and cognitive skills: Mechanism underlying children's school enrollment in Zambia, Developmental Psychology vol. 51, no. 5, 2015, p. 600

[8] Morgan Kristiana E., The Cognitive Effects of chronic malnutrition and environtment on working memory and executive function in children (Independent Study Project (ISP) Collection, paper 2053, 2015)

[9] Selvam Sumithra, Tinku Thomas, Priya Shetty, et al, Development of norms for executive functions in typicallydeveloping Indian urban preschool children and its association with nutritional status, Child Neuropsychology, http:// dx. doi. org/ 10. 1080/ 09297049. 2016.1254761, 2016

[10] Pauli-Pott Ursula, Ozgur Albayrak, Johannes Hebebrand, et al, Association between inhibitory control capacity and body weight in overweight and obese children and adolescents: dependence on age and inhibitory control component (Child Neuropsychology, vol. 16, 2010) hh. 592-603 